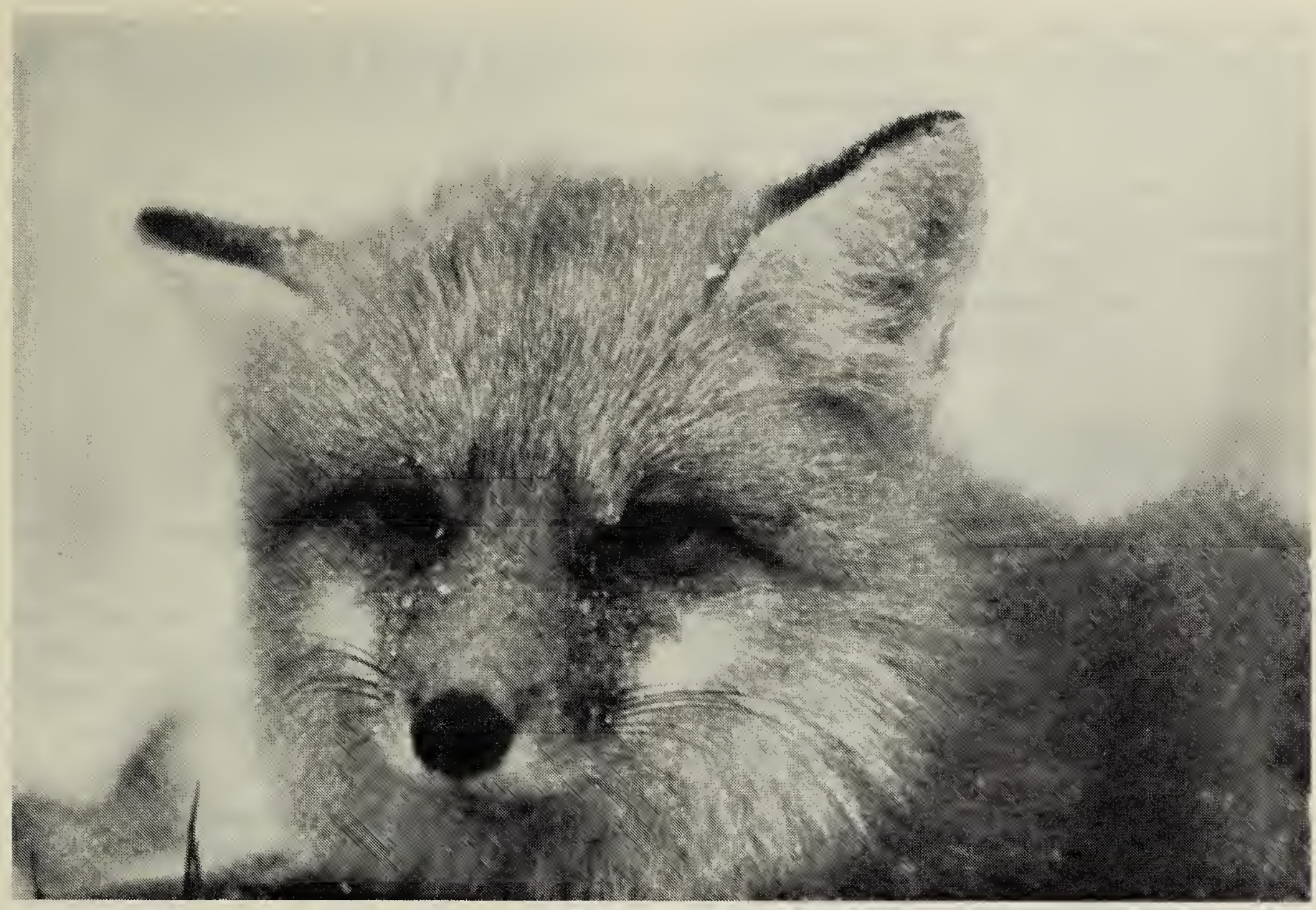

Red Fox

Wayne Lynch

\title{
AN ACTIVE PRAIRIE RATTLESNAKE DEN TAKEN OVER BY FOXES
}

MALCOLM STARK, Lethbridge Community College, Lethbridge, Alberta. T1K 1L6

Although prairie rattlesnakes are found in northern latitudes, they cannot withstand exposure to extremes of heat or cold. In southern Alberta, the last refuges of prairie rattlesnakes are the deep, dry ravines called coulees. One of these coulees, dubbed Rattlesnake Coulee by the farmer who owns the land, lies $3 \mathrm{~km}$ south of Lethbridge. The area receives from 30 to $40 \mathrm{~cm}$ of precipitation annually, but only $22 \mathrm{~cm}$ fall during the growing season. Temperatures can range from $40^{\circ} \mathrm{C}$ to $-42^{\circ} \mathrm{C}$. Hence, rattlesnakes must have access to shade to prevent overheating in summer, and hibernacula (dens) below the frostline to escape freezing in winter. Depth and dryness are two essential requirements of a suitable hibernaculum (rattlesnakes will not hibernate in areas subject to flooding).

Hibernacula in Rattlesnake Coulee are all found on south-facing slopes and include sinkholes, subterranean cracks, and occasionally, vacated burrows of badgers (rattlesnakes do not burrow). Since 1983 I have been observing prairie rattlesnakes occupying one specific, active (sinkhole) hibernaculum. Although the total number of rattlesnakes returning to the hibernaculum for the winter of 1985-1986 was 
not recorded, their coiled imprints were present in the sandy soils around its entrance (no other species of snakes used the hibernaculum). Rattlesnakes are coldblooded and depend on external sources for heat. Therefore, before their retreat underground for the winter, they often bask in the sun at hibernaculum entrances for a few hours on warm days.

In the spring of 1986 (before snowmelt), the immediate area around the hibernaculum entrance was heavily trodden and denuded of most vegetation (heavy sage brush originally encircled the entrance); the hibernaculum was occupied by a fox family (an adult male, an adult female and 3 young). No rattlesnakes were observed leaving the hibernaculum during the spring, nor were any found in the general vicinity of the hibernaculum during the summer. It was not known for certain what happened to the rattlesnakes emerging from the hibernaculum. The author was aware of only one exit from the hibernaculum and it is probable that the rattlesnakes were killed and eaten by the foxes when they emerged.

Prairie rattlesnakes are an integral part of the prairie ecosystem and are important natural predators of ground-nesting birds and rodents. However, from the information collected thus far, it appears that the survival of prairie rattlesnakes is at best precarious in southern Alberta. In addition to the natural predators (coyotes, badgers, raptors, bullsnakes, and foxes, which are increasing in number in southern Alberta), loss of native habitat due to widespread cultivation and irrigation, and indiscriminate killings by man are taking their toll on the numbers of rattlesnakes. The summer of 1986 was the first time that the farmer who owns Rattlesnake Coulee did not see a rattlesnake (he is 60 years old, and was born and raised within a stone's throw of the coulee). It was also the first time since the study began that the author did not see a rattlesnake.
1 STARK, M.A. 1985. A simple technique for trapping prairie rattlesnakes during spring emergence. Herp. Review 16:75-76.

\section{COYOTES EATING HAWTHORN FRUIT}

LAWSON G. SUGDEN, 908 University Drive, Saskatoon, Saskatchewan. S7N 0K1

On 17 November 1986 I observed three coyotes eating the fruits (pomes) of roundleaved hawthorn near Pike Lake, Saskatchewan. It was a clear day with a temperature of $-15 \mathrm{C}$; there was $8 \mathrm{~cm}$ of snow on the ground. When I first noticed the coyotes at about $75 \mathrm{~m}$ distance, the three were watching me. Within a minute, however, they started feeding on clusters of fruit, stretching their necks to reach the lower branches. The tree was about $3 \mathrm{~m}$ tall. One soon stopped to watch me again, but the others continued to feed until I left after about 5 minutes. During that time one stood on its hind legs and rested its front paws on a limb to feed on higher clusters.

There was an abundant crop of hawthorn fruit in the vicinity; the red clusters were large and many were within reach of a coyote. Chokecherries also were abundant but most of the fruit was beyond a coyote's reach. Considering the omnivorous nature of their diet, it is not surprising that coyotes should take advantage of such an abundant food. Sperry (1941:62, Food habits of the coyote, U.S. Dept. of Interior, Fish and Wildlife Service, Wildlife Research Bull. 4) found 120 and 440 hawthorn "apples" in two coyote stomachs from Washington and Idaho, respectively. (Altogether, 8,339 stomachs were examined). Observing such feeding behavior is a rare event. 